\title{
Adsorção de monóxido de carbono em carvão ativado convencional e impregnado com $5 \%$ de nióbio
}

\author{
Carbon monoxide adsorption on \\ conventional activated carbon \\ and impregnated with $5 \%$ niobium
}

\author{
Elson Oliveira $^{1}$, Beatriz Bonk ${ }^{1}$, Erika Pereira Felix ${ }^{1}$ \\ Roberta Caroline Pelissari Rizzo Domingues ${ }^{1}$
}

\footnotetext{
${ }^{1}$ Laboratório de Adsorventes e Catalisadores - LadCat, DAQBi/UTFPR CP: 5000, CEP: 81280-340, Curitiba, PR, Brasil e-mail: elsonutfpr@gmail.com, bia.bonk@gmail.com, erikafelix@utfpr.edu.br, robertac@utfpr.edu.br
}

\begin{abstract}
RESUMO
A poluição atmosférica e o aquecimento global são problemas que vêm se agravando ao longo das décadas devido, principalmente, as atividades antrópicas. Os processos de combustão nas indústrias e nos veículos automotores liberam na atmosfera quantidades consideráveis de poluentes gasosos e material particulado. Neste contexto, o presente trabalho buscou avaliar a eficiência do carvão ativado convencional e impregnado com 5\% de nióbio na adsorção de monóxido de carbono. Os adsorventes foram caraterizados por análises de espectroscopia no infravermelho por transformada de Fourier - FTIR, microscopia eletrônica de varredura MEV, adsorção/dessorção de $\mathrm{N}_{2}$ e difratometria de raios X - DRX. Os estudos de adsorção dinâmica foram realizados com massa de adsorvente igual a $3,5 \mathrm{~g}$, em leito fixo com vazão de $500 \mathrm{~mL} \mathrm{~min}{ }^{-1}$ de mistura de 500 ppm de $\mathrm{CO}$ em $\mathrm{N}_{2}$, com sistema de análise gasosa com célula eletroquímica, em temperatura ambiente. Pelos resultados das caracterizações, observou-se que a presença de nióbio na estrutura do adsorvente levou a uma diminuição na área superficial e volume de poros do carvão ativado, porém com um certo aumento das dimensões dos poros observado por MEV. Em relação aos ensaios de adsorção, o resultado de melhor eficiência ocorreu com o adsorvente carvão/5\% de nióbio; a presença do metal no material adsorvente resultou em um aumento no teor de oxigênio, favorecendo o processo de adsorção. Os dados experimentais de adsorção em leito fixo, para ambos os adsorventes, obedeceram um modelo de distribuição não-linear sigmoidal de Boltzmann. Pelos resultados dos ensaios de adsorção de CO, pode-se afirmar que os desempenhos dos adsorventes foram eficazes, sendo um processo promissor na minimização de emissões desse poluente.
\end{abstract}

Palavras-chave: adsorção; monóxido de carbono; caracterização físico química; carvão ativado; nióbio.

\begin{abstract}
Air pollution and global warming are problems that have been worsening over the decades mainly due to human activities. The combustion process in industries and motor vehicles releases considerable amounts of gaseous pollutants into the atmosphere. In this context, the present work aims to evaluate the efficiency of conventional activated carbon and impregnated with 5\% niobium in the adsorption of carbon monoxide. The adsorbents were characterized by Fourier transform infrared spectroscopy - FTIR, scanning electron microscopy - SEM, $\mathrm{N}_{2}$ adsorption / desorption and X-ray diffraction - XRD. The dynamic adsorption studies were carried out with an adsorbent mass equal to $3.5 \mathrm{~g}$ in a fixed bed with a flow rate of $500 \mathrm{~mL} \mathrm{~min}{ }^{-1}$ of a mixture of $500 \mathrm{ppm} \mathrm{CO}$ in $\mathrm{N}_{2}$ with a gas analysis system with an electrochemical cell at room temperature. From the results of the characterizations, it was possible to observe that the presence of niobium in the adsorbent structure led to a decrease in the surface area and pore volume of the activated carbon, but with a certain increase in the pore dimensions observed by SEM. Regarding the adsorption tests, the result of better efficiency occurred with the adsorbent coal / 5\% niobium, the presence of niobium in the adsorbent material obtained an increase in oxygen, favoring the adsorption process. The experimental data of fixed bed adsorption for both adsorbents obeyed a Boltzmann sigmoidal nonlinear distribution model. The results of the CO adsorption
\end{abstract}


tests can be said that the performance of the adsorbents conventional activated carbon and activated carbon with impregnated niobium are effective in the adsorption of $\mathrm{CO}$, being a promising process in minimizing carbon monoxide emissions.

Keywords: adsorption; carbon monoxide; physical and chemical characterization; activated carbon; niobium.

\section{INTRODUÇÃO}

A poluição atmosférica, e todas as consequências trazidas por ela, é um assunto de grande importância e preocupação, devido aos impactos negativos ao ambiente e aos organismos vivos [1, 2]. A Organização Mundial da Saúde (OMS) classificou o ar poluído como fator carcinogênico, estabelecendo correlações entre poluentes e câncer, principalmente de pulmão e bexiga [3]. Neste sentido, é comum a divulgação na mídia atual de reportagens acerca do assunto, especialmente porque dados científicos têm mostrado que as concentrações de gases e partículas na atmosfera vêm crescendo ao longo das décadas, principalmente em decorrência das emissões por atividades industriais e veículos automotores. Os principais gases liberados por estes veículos são $\mathrm{CO}_{2}, \mathrm{CO}, \mathrm{NO}_{\mathrm{x}}$ e $\mathrm{SO}_{x}$, que constituem poluentes atmosféricos comumente encontrados em diferentes regiões do mundo [4-10].

O monóxido de carbono (CO), um dos gases resultantes da combustão incompleta, é tóxico para homens e animais e, quando inalado, difunde-se para a corrente sanguínea a partir dos alvéolos pulmonares. Por possuir uma afinidade 250 vezes maior que o oxigênio pela hemoglobina contida nos glóbulos vermelhos do sangue, liga-se a ela, dificultando o transporte de oxigênio para o organimo, o que pode resultar em óbito [11, -15]. Em termos de legislação, é um dos poluentes contemplados na Resolução CONAMA 491/18, que dispõe sobre padrões de qualidade do ar. O padrão final, referente a máxima média móvel obtida em $8 \mathrm{~h}$, é de 9 ppm [16]. No Paraná, a Lei Estadual 13806/02 estabelece que para as fontes de poluição móveis, os padrões de emissão são os mesmos adotados pela Resolução CONAMA 03/90 [17], que foi revogada e substituída pela Resolução CONAMA 491/18. Para as fontes estacionárias, os limites de emissão são definidos pela Resolução SEMA 16/14 [18].

Uma das possíveis alternativas para tentar minimizar a emissão de gases poluentes é através do uso de métodos de adsorção. Esta operação unitária envolve um fenômeno de transporte no qual ocorre transferência de massa, devido ao gradiente de concentração existente entre o fluido e a superfície do adsorvente [19]. Os materiais sólidos empregados na adsorção são porosos e com elevada razão área/volume. Bons exemplos de adsorventes, comumente utilizados, são o carvão ativado [20, 21], aluminas [22, 23] e as zeólitas [24, 25].

Ao longo dos anos, estudos vêm sendo realizados a fim de avaliar a capacidade de adsorção do carvão ativado, devido a sua estrutura microcristalina porosa e área superficial relevantes, que apresentam uma eficiência considerável na remoção de compostos indesejáveis de uma mistura gasosa ou líquida [24, 26, 27]. A impregnação de elementos químicos na superfície dos adsorventes podem levar a um melhor desempenho frente ao processo, como por exemplo, o elemento químico nióbio.

O nióbio é um metal de aplicações industriais, em vários materiais supercondutores, bem como aplicações catalíticas sendo largamente investigado, principalmente no Brasil, pois $98 \%$ das reservas mundiais se encontram em território brasileiro, sendo seu baixo custo outro atrativo para utilização [28]. É bastante empregado na metalurgia, na catálise e em pesquisas tecnológicas [29]. A aplicabilidade do $\mathrm{Nb}_{2} \mathrm{O}_{5} \cdot \mathrm{nH}_{2} \mathrm{O}$ está relacionada com suas características texturais ácidas, que dependem do tratamento térmico utilizado em seu processo de síntese [30], podendo formar óxidos de nióbio, cujo o aumento de oxigênio superficial favore a adsorção de monóxido de carbono.

Neste contexto, o presente trabalho teve por objetivo sintetizar, caracterizar e avaliar a capacidade de adsorção de carvão ativado convencional e impregnado com 5\% de nióbio na adsorção de monóxido de carbono $(\mathrm{CO})$ em coluna de leito fixo.

\section{MATERIAIS E MÉTODOS}

\subsection{Preparo e impregnação dos adsorventes}

O processo de impregnação iniciou-se com a preparação de uma solução de ácido nióbico (HY-340 CBMM, com pureza de $76,2 \%$ de $\left.\mathrm{Nb}_{2} \mathrm{O}_{5}\right)$ e ácido oxálico $\left(0,5 \mathrm{~mol} \cdot \mathrm{L}^{-1}\right)$, na proporção de $34,3 \mathrm{~mL}$ de solução/g de ácido nióbico, para a obtenção da solução com teor 5\% Nióbio. A suspensão reagiu em estufa por $24 \mathrm{~h}$ a $70{ }^{\circ} \mathrm{C}$ para a completa solubilização.

A solução de nióbio preparada foi colocada, junto com o carvão ativado Ultraporus 6x12 em forma granular fornecido pela Fábrica Brasileira de Catalisadores (FBC)., em um balão de fundo redondo e em um 
rotaevaporador (MARQLABOR), à $75^{\circ} \mathrm{C}$, o qual estava conectado a uma bomba de vácuo a uma pressão de $450 \mathrm{mmHg}$, onde a proporção de carvão ativado em relação a solução foi estabelecida para obter uma porcentagem mássica de 5\% de nióbio em carvão ativado convencional. Após evaporação, o carvão ativado impregnado foi colocado em forno mufla por $5 \mathrm{~h}$ à $150{ }^{\circ} \mathrm{C}$.

O carvão ativado comercial utilizado na forma de pastilha, tanto convencional quanto o impregnado com $5 \%$ de nióbio, foram macerados manualmente e peneirados, a fim de se obter uma granulometria uniforme do adsorvente. A granulometria média utilizada neste estudo foi de $0,07 \mathrm{~cm}$.

\subsection{Caracterizações}

Os adsorventes foram caracterizados por difratometria de raios-X, em equipamento da marca Shimadzu, modelo XDR-700. As medidas foram realizadas usando radiação $\mathrm{CuK} \alpha \operatorname{com} 30 \mathrm{kV}$ e $15 \mathrm{~mA}$ na faixa de $2 \theta$ de $10^{\circ}$ a $100^{\circ}$ na velocidade de $2^{\circ} \mathrm{min}^{-1}$.

Os espectros de absorção na região do infravermelho (de 4000 a $400 \mathrm{~cm}^{-1}$ ) foram registrados em um espectrofotômetro Varian, modelo 640 IR. Para o preparo das amostras, foi utilizado o método de pastilhamento com $\mathrm{KBr}$.

As análises de MEV/EDS foram feitas em um equipamento Zeiss, série EVO MA15. As medidas foram realizadas com tensões de aceleração de 1 a $50 \mathrm{kV}$ em filamento de tungstênio, com ampliação de até 1000 vezes.

As análises de adsorção/dessorção de $\mathrm{N}_{2}$ foram realizadas em equipamento Quanta Chrome Nova. A área específica foi calculada usando o método de Brunauer-Emmett-Teller (BET) na faixa de pressão relativa (P/P0) entre 0,04 - 1,0. Para os demais parâmetros, foram utilizados os métodos t e BJH. As amostras foram pré-tratadas em um sistema a vácuo, com temperatura de $353 \mathrm{~K}$ durante $3 \mathrm{~h}$ e $30 \mathrm{~min}$, a fim de remover possíveis impurezas do material.

\subsection{Ensaios de adsorção}

O processo de adsorção ocorreu em coluna de leito fixo, consistindo em um tubo de aço inox com dimensões de $36 \mathrm{~cm}$ de altura e 2,1 cm de diâmetro interno. A coluna foi preenchida com 3,5 g de adsorvente, colocado entre duas camadas de esferas de vidro, resultando em uma altura de $2,8 \mathrm{~cm}$. Como as esferas de vidro são constituídas de um material inerte, foram utilizadas para o preenchimento dos espaços vazios, a fim de completar a altura total do leito de adsorção.

O fluxo de gás injetado no leito foi em regime ascendente, sendo realizada a limpeza da superfície do material com $\mathrm{N}_{2}$ durante $2 \mathrm{~h}$, a uma vazão de $200 \mathrm{~mL} \mathrm{~min}^{-1}$. Um fluxímetro possibilitou o ajuste e controle das vazões dos gases. A Figura 1 apresenta o esquema da unidade de adsorção.

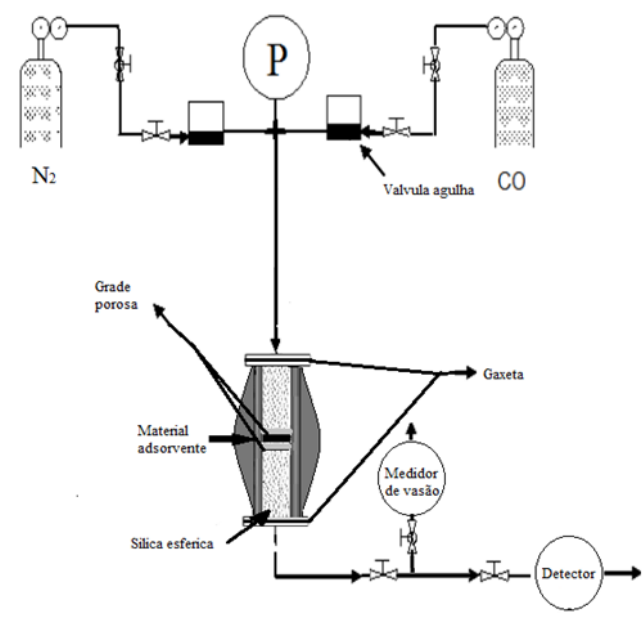

Figura 1: Esquema da unidade de adsorção.

Após a limpeza da superfície do adsorvente com $\mathrm{N}_{2}$, iniciou-se a adsorção com a passagem da mistura gasosa $\mathrm{CO} / \mathrm{N}_{2}$ pelo sistema, com uma concentração de $500 \mathrm{ppm}$ de $\mathrm{CO}$ e um fluxo de $500 \mathrm{~mL} \mathrm{~min}{ }^{-1}$., em temperatura ambiente e pressão do gás referente a saída do cilindro de aproximadamente 5 psia. A saída dos 
gases na parte superior do reator foi acoplada ao detector (Modelo Ecil 2000 - analisador de gases - célula eletroquímica), a fim de realizar a leitura da concentração de CO. Após os testes de adsorção, os resultados foram plotados para a construção da curva de ruptura (C/Co vs. t). O volume total de $\mathrm{CO}$ adsorvido (Vads) foi obtido conforme a equação 1 [31] e a área da curva de ruptura foi determinada pela integração da área da fração molar adsorvida versus tempo total da adsorção.

$$
v_{a d s}=Q \cdot \int_{0}^{t}\left(1-c / c_{c_{0}}\right) d t
$$

\section{Onde:}

$\mathrm{C}_{\mathrm{O}}=$ fração molar inicial do $\mathrm{CO}$;

$\mathrm{C}=$ fração molar de saída do $\mathrm{CO}$;

$\mathrm{Q}=$ vazão volumétrica $\left(\mathrm{mL} \mathrm{min}^{-1}\right)$;

$\mathrm{t}=$ tempo $(\min )$.

O volume total de $\mathrm{CO}$ alimentado $\left(V_{a l .} m L^{-1}\right)$ foi encontrado pela multiplicação da vazão volumétrica $\left(Q / \mathrm{mL} \mathrm{min}^{-1}\right)$ pelo tempo total $(\mathrm{t} / \mathrm{min})$ ocorrido da adsorção, como mostra a equação 2 [31]

$$
v_{a l}=Q \cdot t_{\text {total }}
$$

A eficiência de remoção em porcentagem $\left(\eta_{\mathrm{Co}}\right)$ de $\mathrm{CO}$ foi calculada pela razão entre o volume total de $\mathrm{CO}$ adsorvido (Vads) e o volume total de CO alimentado (Val), conforme Equação 3 [31].

$$
\eta_{\mathrm{CO}}=\left(v_{a d s} / v_{a l}\right) .100
$$

A capacidade de adsorção $\left(m_{C O / C A}\right)$ foi calculada através da Equação 4, a partir do volume de $\mathrm{CO}$ adsorvido no ensaio (Vads), considerando a massa molar do efluente $\left(\mathrm{M}_{C O}\right)$ de 28 g.mol ${ }^{-1}$ [32] e o volume ideal (Vid) de 22,4 L.mol ${ }^{-1}$, em condições normais de temperatura de pressão - CNTP [33], de acordo com a teoria de Clapeyron dos gases ideais [34]. A massa de adsorvente utilizada $\left(m_{C A}\right)$ foi de $3,5 \mathrm{~g}$.

$$
m_{C O / C A}=\frac{\left(M_{C O} \cdot V_{a d s}\right)}{V_{i d} \cdot m_{C A}}
$$

A curva de efluência foi modelada pela distribuição não-linear sigmoidal de Boltzmann, apresentada na Equação 5 [35].

$$
Y=\frac{\left(A_{1}-A_{2}\right)}{1+e^{\left(x_{0}-X\right) / d x}}+A_{2}
$$

A linha de tendência foi obtida usando o software SciDAVis, para obter os parâmetros deste estudo, onde $\mathrm{X}$ é o tempo em minutos, $\mathrm{Y}$ é a relação $\mathrm{C} / \mathrm{C}_{0}, \mathrm{~A}_{1}$ representa a assíntota superior, momento no qual ocorre a máxima adsorção de gás, ou seja, o ponto de ruptura, $\mathrm{A}_{2}$ corresponde a assíntota inferior e refere-se a $\mathrm{C} / \mathrm{C}_{0}$ no ponto de saturação, equivalente a $\mathrm{C} / \mathrm{C}_{0}$ inicial, $\mathrm{dx}$ a inclinação da curva no tempo, que depende de vários parâmetros como vazão, altura e massa do adsorvente no leito, difusão de poros, entre outros; $x_{0}$ representa o ponto de inflexão da curva, ou seja, o ponto da curva de ruptura na condição ideal $\left(\mathrm{t}_{\mathrm{id}}\right)$, onde $95 \%$ da coluna está saturada, ou seja quando $\mathrm{C} / \mathrm{C}_{0}$ é aproximadamente igual a 1 [29, 31, 35]. Para o método gráfico o ponto de ruptura, geralmente designado por $\mathrm{C}_{\mathrm{b}}$, é escolhido como sendo o ponto em que a relação de C/Co é igual a $0,05\left(5 \%\right.$ de $\left.\mathrm{C}_{\mathrm{b}} / \mathrm{C}_{0}\right)$.

\section{RESULTADOS}

\subsection{Caracterização dos materiais}

Na Figura 2 estão apresentados os difratogramas obtidos nas análises de DRX para as amostras de carvão ativado convencional e impregnado com $5 \%$ de nióbio. 


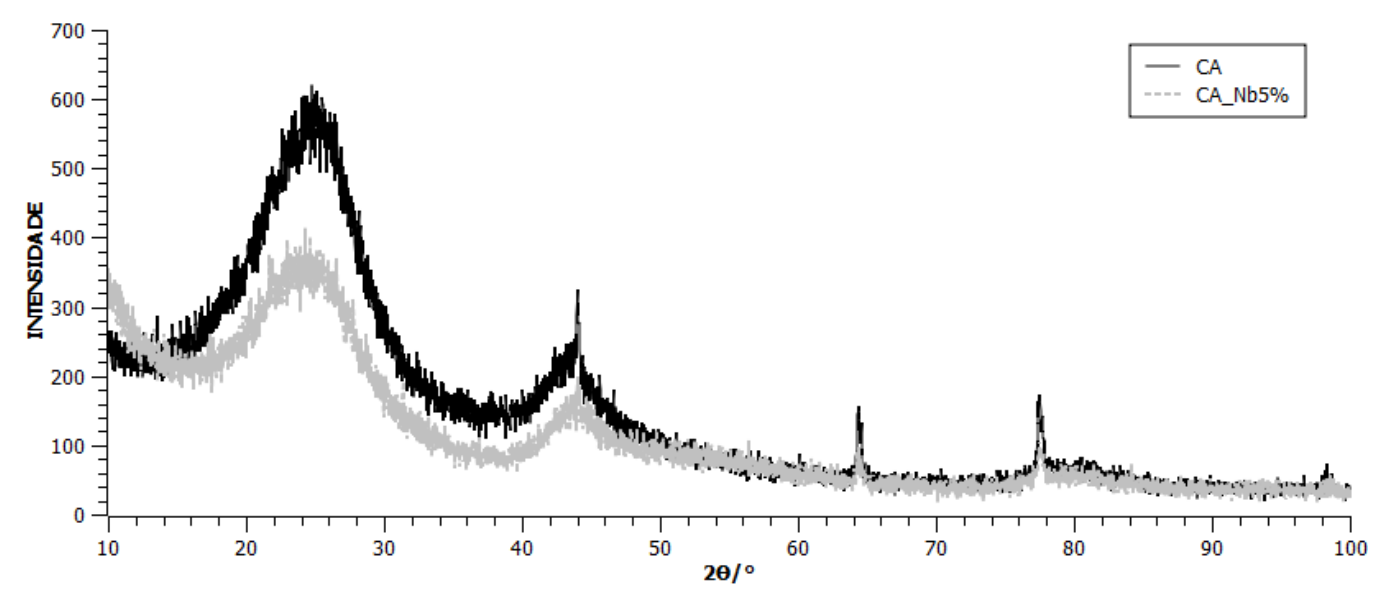

Figura 2: Difratogramas das amostras de Carvão ativado convencional ( - CA) e Carvão ativado impregnado com 5\% (--CA_Nb5\%) de Nióbio.

Os grupos funcionais presentes no carvão ativado convencional, detectados pela Espectroscopia de Infravermelho por Transformada de Fourier (FTIR), estão representados na Figura 3, onde: A) Vibração de alongamento simétrica $\left(\mathbf{v}_{\mathrm{s}}\right)$ : aromático do $=\mathrm{C}-\mathrm{H}, 3550,40 \mathrm{~cm}^{-1}$. B) Vibração antissimétrica $\left(\mathbf{v}_{\mathrm{as}}\right)$ : aromático do $=\mathrm{C}-\mathrm{H}, 3477,11 \mathrm{~cm}^{-1}$. C) $\mathbf{v}_{\mathrm{as}}$ aromático do $=\mathrm{C}-\mathrm{H}, 3431,47 \mathrm{~cm}^{-1}$. D) $\mathbf{v}_{\mathrm{as}}$ aromático do $\mathrm{C}=\mathrm{C}, 2360,50 \mathrm{~cm}^{-1}$. E) $\mathbf{v}_{\mathrm{s}}$ aromático do $\mathrm{C}=\mathrm{C}, 2339,29 \mathrm{~cm}^{-1}$. F) $\mathbf{v}_{\text {as }}$ do $\left.\mathrm{C}=\mathrm{C}, 1637,31 \mathrm{~cm}^{-1} \mathrm{G}\right) \mathbf{v}_{\mathrm{s}}$ do $\mathrm{C}=\mathrm{C}, 1618,02 \mathrm{~cm}^{-1}$. H) $\boldsymbol{\delta}_{a s}$ no plano, $=\mathrm{C}-\mathrm{H}, 622,91 \mathrm{~cm}^{-1}$. I) deformação não identificada, 478,27 $\left.\mathrm{cm}^{-1} . \mathrm{J}\right) \mathbf{v}_{s}$ aromático do $\left.=\mathrm{C}-\mathrm{H}, 3550,40 \mathrm{~cm}^{-1} . \mathrm{K}\right)$ $\mathbf{v}_{\mathrm{as}}$ aromático do $=\mathrm{C}-\mathrm{H}, 3477,11 \mathrm{~cm}^{-1}$. L) $\mathbf{v}_{\mathrm{as}}$ aromático do $\left.=\mathrm{C}-\mathrm{H}, 3431,47 \mathrm{~cm}^{-1} . \mathrm{M}\right) \mathbf{v}_{\mathrm{as}}$ aromático do $\mathrm{C}=\mathrm{C}$, $2358,48 \mathrm{~cm}^{-1}$. N) $\mathbf{v}_{\mathrm{s}}$ aromático do $\mathrm{C}=\mathrm{C}, 2337,36 \mathrm{~cm}^{-1}$. O) $\mathbf{v}_{\text {as }}$ do $\mathrm{C}=\mathrm{C}, 1637,31 \mathrm{~cm}^{-1}$. P) $\mathbf{v}_{\mathrm{s}}$ do $\mathrm{C}=\mathrm{C}, 1618,02$ $\mathrm{cm}^{-1}$. Q) $\boldsymbol{\delta}_{\text {as }}$ no plano, $=\mathrm{C}-\mathrm{H}, 620,98 \mathrm{~cm}^{-1}$. R) deformação não identificada $476,34 \mathrm{~cm}^{-1}$. [19].

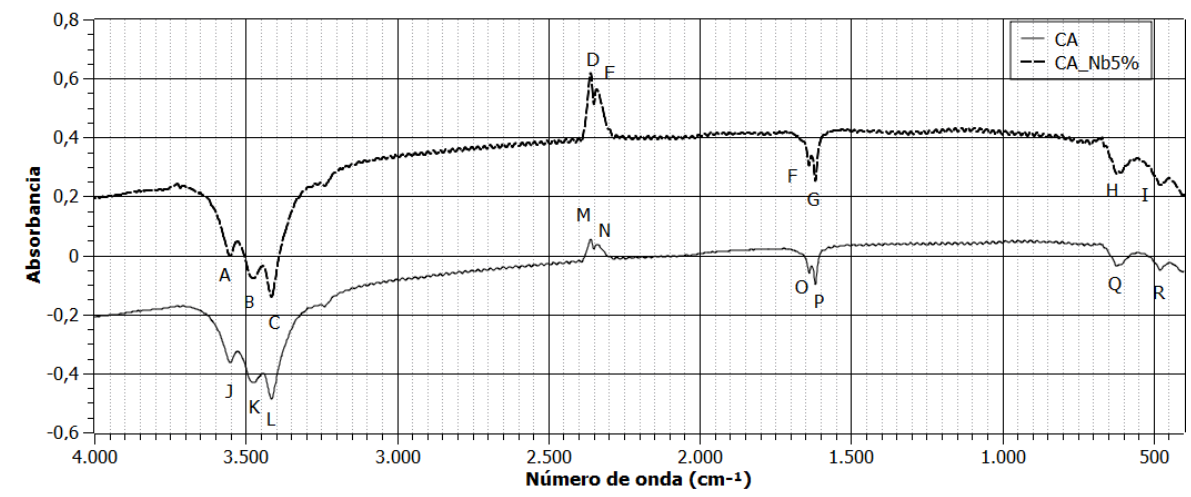

Figura 3: Espectro FTIR das amostras de Carvão ativado convencional (— CA) e Carvão ativado impregnado com 5\% (--CA_5\%) de Nióbio.

Os resultados de microscopia eletrônica de varredura e os dados do espectroscopia por energia dispersiva dos materiais sintetizados estão representados na Figura 4 e Tabela 1, respectivamente. 

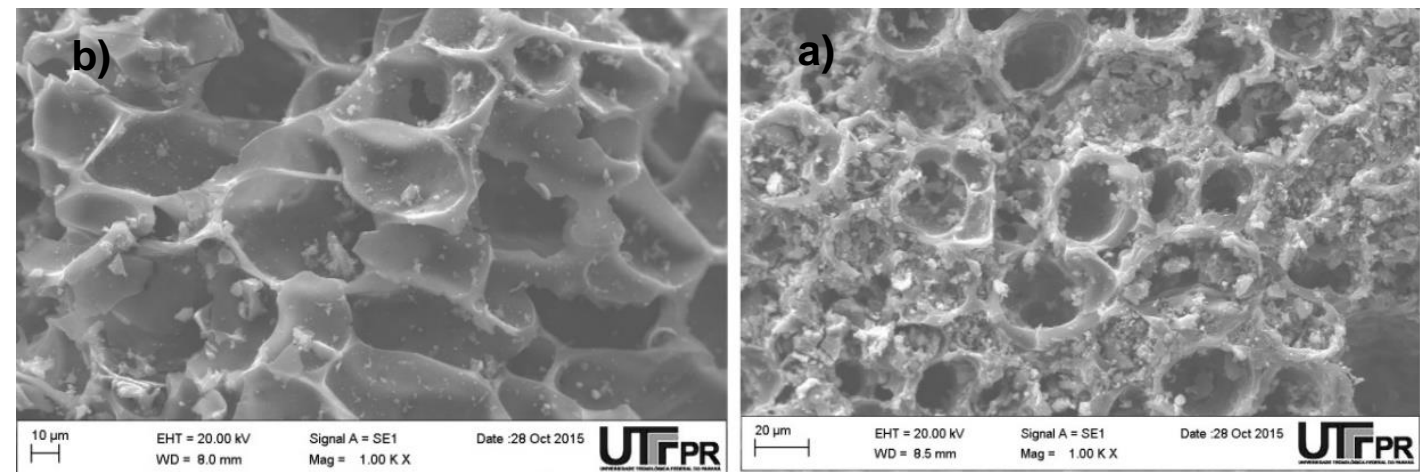

Figura 4: Micrografias das amostras de a) carvão ativado convencional e b) carvão ativado impregnado com 5\% de Nióbio.

Tabela 1: Dados obtidos por espectroscopia por energia de dispersão

\begin{tabular}{c|c|c|c|c|c|c|c|c|c|c|c}
\hline MATERIAL & $\mathbf{C} / \%$ & $\mathbf{O} / \%$ & $\mathbf{S} / \%$ & $\mathbf{F e} / \%$ & $\mathbf{C a} / \%$ & $\mathbf{K} / \%$ & $\mathbf{M g} / \%$ & $\mathbf{S i} / \%$ & $\mathbf{A l} / \%$ & $\mathbf{T i} / \%$ & $\mathbf{N b} / \%$ \\
\hline Carvão ativado convencional & 95,04 & 4,57 & 0,14 & 0,24 & 0 & 0 & 0 & 0 & 0 & 0 & 0 \\
\hline Carvão com 5\% Nb & 87,42 & 10,34 & 0 & 0,03 & 0,06 & 0,28 & 0,07 & 0,12 & 0,04 & 0 & 1,64 \\
\hline $\pm 0,01 \%$
\end{tabular}

A análise de adsorção/dessorção de $\mathrm{N}_{2}$ dos adsorventes está apresentada na Tabela 2, onde estão os valores referentes a área superficial $\left(\mathrm{S}_{\mathrm{BET}}\right)$, volume $\left(\mathrm{V}_{\text {total de poro }}\right)$ e diâmetro de poros $(\Phi)$.

Tabela 2: Resultados da análise de adsorção/dessorção de $\mathrm{N}_{2}$ dos adsorventes.

\begin{tabular}{c|c|c|c}
\hline MATERIAL & $\mathbf{S}_{\mathrm{BET}} /\left(\mathbf{m}^{\mathbf{2}} \mathbf{g}^{-\mathbf{1}}\right)$ & $\mathbf{V}_{\text {total de poro }} /\left(\mathbf{c m}^{\mathbf{3}} \mathbf{g}^{-\mathbf{1}}\right)$ & $\mathbf{\Phi} / \mathbf{\AA}$ \\
\hline Carvão ativado convencional & $749,16 \pm 0,01$ & $0,077 \pm 0,001$ & $15,23 \pm 0,01$ \\
\hline Carvão com $5 \% \mathrm{Nb}$ & $672,41 \pm 0,01$ & $0,067 \pm 0,001$ & $15,22 \pm 0,01$ \\
\hline
\end{tabular}

\subsection{Adsorção em leito fixo - curva de ruptura}

Os resultados dos ensaios de adsorção mostrados na Figura 5 a) foram obtidos nos ensaios de adsorção desde o instante zero até o final da adsorção, onde mostra a concentração efluente de monóxido de carbono em realçao ao tempo, já a Figura 5 b) mostra a curva de ruptura da adsorção de $\mathrm{CO}$ nos materiais adsorventes que ocorreu a partir do instante onde a adsorção máxima de $\mathrm{CO}$ aconteceu, ou seja, após aproximadamente 48 min do início do ensaio, sendo, com isso, permitido a modelagem da adsorção pela equação de distribuição não-linear sigmoidal de Boltzmann para cada um dos adsorventes. 

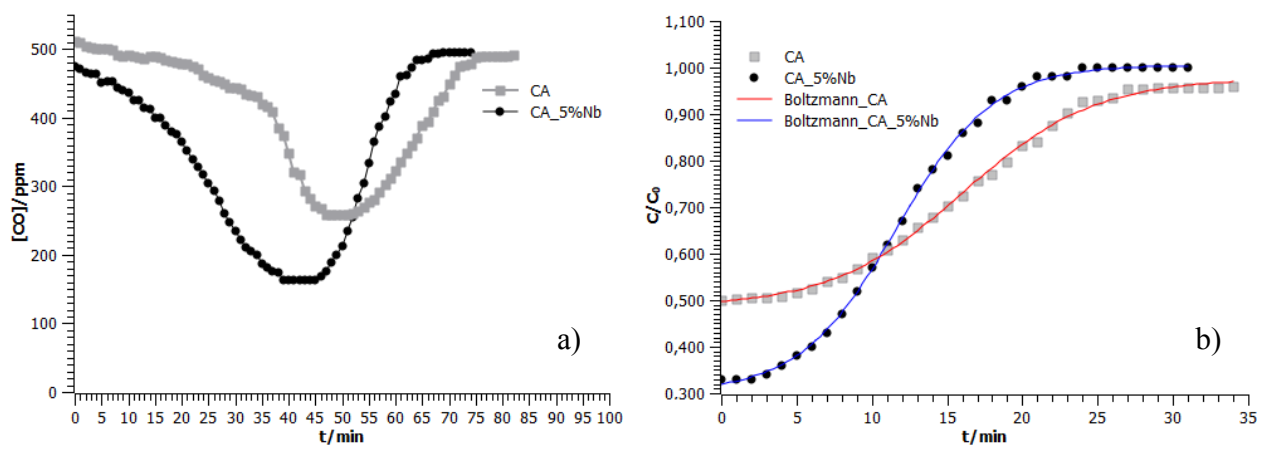

Figura 5: Adsorção de $\mathrm{CO}$ em leito fixo com os adsorventes: a) Ensaio de adsorção completo de carvão ativado convencional ( CA ) e carvão ativado impregnado com 5\% de Nióbio ( CA_5\% ) em relação a concentração de CO na saída do sistema (gás efluente). b) Curva de ruptura: C/C0 (Concentração de CO efluente pela concentração de CO afluente) em relação ao tempo,e; curva de ruptura modelada pela equação de distribuição não-linear sigmoidal de Boltzmann para cada um dos adsorventes. saio.

O gráfico da Figura 6 foi gerado a partir da Equação 1, que apresenta o volume de gás adsorvido no en-


Figura 6: Volume adsorvido do $\mathrm{CO}$ em leito fixo em função do tempo com o carvão ativado convencional e impregnado com 5\% de Nióbio: a) tempo total de ensaio. b) tempo a partir do instante máximo de adsorção.

A Tabela 3 apresenta a capacidade de adsorção do carvão ativado convencional e impregnado com nióbio ao logo de todo o tempo de ensaio, aproximadamente $80 \mathrm{~min}$, obtido dos pontos da Figura 6 a). A Tabela 4 apresenta os dados da curva de efluência obtida na Figura 6 b), em que mostra os dados a partir do instante máximo de adsorção (mínima detecção de $\mathrm{CO}$ ) que considerou-se como o tempo zero, até a saturação total da coluna, próxima de $30 \mathrm{~min}$.

Os valores do volume adsorvido ( $V a d s$ ) foram determinados pela integração da área abaixo da curva da Figura 6.b; o volume alimentado foi determinado pela equação 2 , a eficiência de remoção ( $\eta_{\mathrm{CO}}$ ) foi obtida pela equação 3 , o ponto de máxima adsorção $\left(C_{m} / g ; t_{m} / \mathrm{min}\right)$ foi obtido a partir da Figura 6 a) e a capacidade de adsorção, que corresponde a massa em gramas de $\mathrm{CO}$ adsorvido dividido pela massa em gramas de adsorvente ulitizado $\left(m_{C O / C A}\right)$, foi determinada pela equação 4 .

Tabela 3: Dados obtidos dos ensaios de adsorção de CO no tempo total (Figura 6.a).

\begin{tabular}{c|c|c|c|c|c}
\hline MATERIAL & $\boldsymbol{V a d s} / \boldsymbol{L}$ & $\boldsymbol{V a l} / \boldsymbol{L}$ & $\boldsymbol{\eta}_{\mathbf{C o}} / \boldsymbol{\%}$ & $\left(\boldsymbol{C}_{\boldsymbol{m}} / \boldsymbol{g}_{;} \boldsymbol{t}_{\boldsymbol{m}} / \mathbf{m i n}\right)$ & $\boldsymbol{m}_{\boldsymbol{C O} / \boldsymbol{C A}} /(\mathbf{g} / \mathbf{g})$ \\
\hline CA & $8,6 \pm 0,1$ & $44,7 \pm 0,6$ & $19,3 \pm 0,4$ & $(258 ; 48) \pm 1$ & $3,09 \pm 0,04$ \\
\hline CA_5\% $\mathrm{Nb}$ & $10,5 \pm 0,2$ & $34,2 \pm 0,5$ & $30,8 \pm 0,6$ & $(163 ; 43) \pm 1$ & $3,76 \pm 0,05$ \\
\hline
\end{tabular}


Tabela 4: Dados obtidos do resultado de ensaio de adsorção de CO na curva de efluência (Figura 6.b).

\begin{tabular}{c|c|c|c|c|c}
\hline MATERIAL & $\boldsymbol{V a d s} / \boldsymbol{L}$ & $\boldsymbol{V a l} / \boldsymbol{L}$ & $\mathbf{\eta}_{\mathbf{C o}} / \boldsymbol{\%}$ & $\boldsymbol{C} / \boldsymbol{C}_{\boldsymbol{O}(\text { inicial })}$ & $\boldsymbol{m}_{\boldsymbol{C O} / \boldsymbol{C A}} /(\mathbf{g} / \mathbf{g})$ \\
\hline CA & $4,8 \pm 0,004$ & $18,5 \pm 0,02$ & $26,3 \pm 0,03$ & $0,504 \pm 0,002$ & $1,74 \pm 0,003$ \\
\hline CA_5\% Nb & $4,2 \pm 0,100$ & $14,3 \pm 0,50$ & $29,0 \pm 1,00$ & $0,329 \pm 0,003$ & $1,50 \pm 0,050$ \\
\hline
\end{tabular}

A Tabela 5 apresenta os parâmetros da equação 5, obtidos através do softwere SciDAVis, a partir dos dados experimentais da curva de efluencia que contam na Figura 5 b).

Tabela 5: Parâmetros obtidos pelo modelo de distribuição sigmoidal de Boltzmann, a partir do ensaio de adsorção de CO pela curva de efluência.

\begin{tabular}{c|c|c|c|c|c}
\hline MATERIAL & $\mathbf{A}_{\mathbf{1}}$ & $\mathbf{A}_{\mathbf{2}}$ & $\mathbf{x}_{\mathbf{0}}$ & $\mathbf{D x}$ & $\mathbf{R}^{\mathbf{2}}$ \\
\hline CA & $0,507 \pm 0,006$ & $1,019 \pm 0,005$ & $16,1 \pm 0,2$ & $4,4 \pm 0,2$ & 0,9980 \\
\hline CA_5\% Nb & $0,301 \pm 0,005$ & $1,006 \pm 0,003$ & $11,65 \pm 0,08$ & $3,21 \pm 0,07$ & 0,9995 \\
\hline
\end{tabular}

Os dados da Tabela 6 apresentam os pontos de ruptura $\left(C / C_{O(r) ;}, t_{r} / \mathrm{min}\right)$, ideal $\left(C / C_{O(i d) ;} t_{i d} / \mathrm{min}\right)$ e de saturação $\left(C / C_{O(s)} ; t_{S} / \mathrm{min}\right)$ pelos resultados dos ensaios de adsorção, a partir da curva de ruptura (Figura $5 \mathrm{~b}$ ) e pela modelagem utilizando a equação de distribuição sigmoidal de Bolztmann.

Tabela 6: Resultados dos ensaios de adsorção a partir da curva de ruptura: ponto de ruptura $\left(C / C_{0(r) ;} t_{r} / \mathrm{min}\right)$, ponto ideal $\left(C / C_{O(i d) ;} ; t_{i d} / \mathrm{min}\right)$ e ponto de saturação $\left(C / C_{O(s)} ; t_{s} / \mathrm{min}\right)$. Comparação com os dados a partir do modelo de distribuição sigmoidal de Bolztmann para o carvão ativado convencional (CA) e impregnado com 5\% de nióbio (CA_5\% Nb).

\begin{tabular}{c|c|c|c|c}
\hline Método & \multicolumn{2}{|c|}{ Gráfico } & \multicolumn{2}{c}{ Distribuiçãa Sigmoidal de Boltzmann } \\
\hline \multirow{2}{*}{ MATERIAL } & CA & CA_5\% Nb & CA & CA_5\% Nb \\
\hline C/C $\mathbf{C}_{\boldsymbol{0}(\mathbf{r})}$ & $0,504 \pm 0,002$ & $0,339 \pm 0,003$ & $0,507 \pm 0,006$ & $0,301 \pm 0,005$ \\
\hline $\boldsymbol{t}_{\boldsymbol{r}} / \mathbf{m i n}$ & $6 \pm 1$ & $3 \pm 1$ & $1 \pm 1$ & $0 \pm 1$ \\
\hline $\mathbf{C}_{\mathbf{C}_{\mathbf{0}(\mathbf{i d})}}$ & $0,758 \pm 0,003$ & $0,475 \pm 0,003$ & $0,725 \pm 0,002$ & $0,673 \pm 0,006$ \\
\hline $\boldsymbol{t}_{\boldsymbol{i d}} / \mathbf{m i n}$ & $17 \pm 1$ & $8 \pm 1$ & $16,10 \pm 0,2$ & $11,65 \pm 0,08$ \\
\hline $\mathbf{C} / \mathbf{C}_{\boldsymbol{0}(\mathbf{s})}$ & $0,953 \pm 0,003$ & $0,956 \pm 0,005$ & $0,977 \pm 0,005$ & $1,000 \pm 0,005$ \\
\hline $\boldsymbol{t}_{\boldsymbol{s}} / \mathbf{m i n}$ & $27 \pm 1$ & $20 \pm 1$ & $>34$ & $26 \pm 1$ \\
\hline
\end{tabular}

\section{DISCUSSÃO}

\subsection{Caracterização dos materiais}

Conforme mostrado na Figura 2, os difratogramas do carvão ativado convencional e impregnado com nióbio não apresentaram linhas de base horizontal, características de material amorfo, como o obtido por BOUCHELTA et. al. [36] utilizando carvão ativado. Nota-se, porém, nos difratogramas das amostras de carvão desta pesquisa alguns picos, contrariando a amorficidade detectada por BOUCHELTA et. al. [34], indicando a presença de material cristalino, mas com intensidade muito baixa, ou seja, poucas estruturas cristalinas. No difratograma da amostra impregnada, não é possível notar picos característicos do óxido de nióbio (V), que ocorrem em 22,6; 28,3 e 36,6 $6^{\circ}$ [37]. Essa ausência de picos não exclui necessariamente a sua presença na superfície da amostra, uma vez que metais em concentrações reduzidas não são detectados pela técnica [38], necessitando o emprego de técnicas analíticas com limites de detecção mais baixos, que possam ser usadas na identificação destes materiais, como a espectroscopia Raman [39].

A partir dos espectros de FTIR apresentados na Figura 3, é possível notar que a presença do nióbio na estrutura do adsorvente provocou pequenas alterações nas intensidades das bandas características do carvão ativado. $\mathrm{Na}$ amostra impregnada foi possível notar o aumento dos sinais analíticos entre os picos da região 
próxima a $2300 \mathrm{~cm}^{-1}$, onde são identificadas as deformações axial simétrica e assimétrica do $\mathrm{C}=\mathrm{C}$ do anel aromático, indicando uma maior polarização, o que evidencia que o pentóxido de nióbio pode ter influênciado nos pares eletrônicos ressonantes do anel. Foi possível constatar a dupla ligação entre os carbonos $(\mathrm{C}=\mathrm{C})$ que geraram duas bandas próximas à $1650 \mathrm{~cm}^{-1}$ [40]. Nota-se também que na região entre 3650 e $3500 \mathrm{~cm}^{-1}$, bandas são referentes a ligaçoes $\mathrm{O}-\mathrm{H}$ e bandas entre 3400 e $3300 \mathrm{~cm}^{-1}$, referentes a C-H [40], podem ser atribuídas aos grupamentos carboxil, lactona, fenol, lactol, carbonil e quinonas do carvão ativado $[41,20]$.

A ligação $\mathrm{Nb}-\mathrm{O}$ dos octaedros de $\mathrm{NbO}_{6}$ levemente distorcidos fornecem bandas entre 500 e $700 \mathrm{~cm}^{-1}$ [42- 44] e o estiramento de uma ligação longa $\mathrm{Nb}-\mathrm{O}-\mathrm{Nb}$ gera banda na região de $600 \mathrm{~cm}^{-1}$ [45]. Em ambos os espectros, é possível observar pequenas bandas nessas regiões, no entanto, não se pode atribuí-las às espécies de nióbio, pois o fenômeno ocorreu em ambas a amostras, carvão convencional e impregnado. Ainda que não tenham sido verificadas bandas referentes ao nióbio, foi possível sua identificação usando MEV/EDS, como mostrado na Tabela 1.

Nas micrografias das análises de MEV, apresentadas na Figura 4, das amostras de carvão ativado convencional e impregnado com nióbio pode-se notar a diferença na superfície do carvão após a impregnação, apresentando uma pequena modificação na abertura dos poros dos materiais, porém deve considerar o fato das escalas de ampliação serem diferentes, portanto é apenas uma suposição desta diferença na superfície dos materiais.

A análise elementar (EDS), cujos resultados estão apresentados na Tabela 1, é considerada qualitativa, pois é realizada de forma pontual, o que dificulta a deteç̧ão do analito, dependendo da heterogeneidade do material. O carvão ativado possui em sua superfície elementos como oxigênio e enxofre, o que explica a presença destes no EDS. Além de hidrogênio, nitrogênio e fósforo [20, 46] Esses elementos são responsáveis pela sua capacidade adsortiva, principalmente o oxigênio, que favorece sítios de adsorção ácidos (carboxil, lactona, fenol e lactol) e básicos (carbonil e grupos quinonas), ou seja, quanto maior a concentração dos átomos de oxigênio na superfície do material, maior a capacidade de adsorção [20, 46]. Pela análise apresentada na Tabela 1, foi possível observar no carvão convencional a presença de oxigênio, ferro, enxofre, entre outros elementos, com caráter tanto básico quanto ácido.

O carvão impregnado apresentou queda na porcentagem de carbono e aumento na porcentagem de oxigênio, apontando que a impregnação possivelmente aumentou sua capacidade adsortiva, visto que os sítios ácidos e básicos provenientes do pentóxido de nióbio e do carvão ativado são mais pronunciados. A presença de nióbio no material impregnado foi detectada, bem como o aumento de oxigênio, que sugere fortemente que o nióbio passou para a forma de óxido, possivelmente de $\mathrm{Nb}_{2} \mathrm{O}_{5}$, sendo esse resultado confirmado na análise de FTIR, onde foi verificado o estiramento de banda na região de $600 \mathrm{~cm}^{-1}$, indicando a presença de $\mathrm{Nb}-\mathrm{O}-\mathrm{Nb}$. Também foi possível notar que alguns metais como $\mathrm{Ca}, \mathrm{Mg}$ e Si foram encontrados em pequenas quantidades após a impregnação, possivelmente devido a impurezas contidas no ácido nióbico.

O carvão ativado é um material constituído estruturalmente de cadeia carbônica fechada amorfa porosa e abrange, de modo geral, micro $(<1 \mathrm{~nm})$, meso $(1-25 \mathrm{~nm})$ e macro poros $(>25 \mathrm{~nm})$, possui altíssima área superficial variando de 800 a $1500 \mathrm{~m}^{2} \mathrm{~g}^{-1}$, em alguns casos atingindo até $4000 \mathrm{~m}^{2} \mathrm{~g}^{-1}$, dependendo das condições de produção $[20,46]$. Em relação a análise de fisissorção de $\mathrm{N}_{2}$, a partir dos dados apresentados na Tabela 2, é possível notar que as áreas superficiais dos materiais, tanto para o carvão ativado convencional quanto impregnado com nióbio, foram elevadas, 749,16 e $672,41 \mathrm{~m}^{2} \mathrm{~g}^{-1}$, respectivamente. Com relação ao volume de poros, obteve-se $0,077 \mathrm{~cm}^{3} \mathrm{~g}^{-1}$ para o carvão convencional e $0,067 \mathrm{~cm}^{3} \mathrm{~g}^{-1}$ para o carvão impregnado. Observa-se que a presença de nióbio na estrutura do adsorvente, levou a uma diminuição na área superficial do carvão ativado, possivelmente em decorrência dos sítios ácido/base do ácido nióbico interagirem com os sítios ácido/base do carvão ativado, ocupando os sítios adsortivos do carvão. Esses resultados indicam também que as partículas contendo nióbio são pequenas o suficiente para ocupar os poros. O diâmetro dos poros se manteve em valores próximos a $15 \AA$, que, segundo a International Union of Pure and Applied Chemistry - IUPAC [33], podem ser classificados como mesoporosos, mostrando que a impregnação não alterou o tipo de estrutura do carvão ativado, mantendo constante a mesoporicidade. Segundo o trabalho de ARAUJO et al. [7], o carvão ativado comercial apresenta uma área superficial alta, $576 \mathrm{~m}^{2} \mathrm{~g}^{-1}$, o que é coerente com os valores encontrados neste trabalho, se fossem considerados tempos iguais de análise.

\subsection{Adsorção em leito fixo - curva de ruptura}

De um modo geral, a utilização de carvão ativado como adsorvente já considerada clássica, desde utilização em tratamento de efluentes líquidos, como mostrado por Ferreira et. al. [47] na adsorção de paracetamol uti- 
lizando carvão ativado de dendê in natura e funcionalizado em meio ácido, bem como em outros processos [48].

Os resultados dos ensaios de adsorção em leito fixo de monóxido de carbono, utilizando os adsorventes carvão ativado convencional e carvão ativado impregnado com $5 \%$ de $\mathrm{Nb}$, mostraram que a adsorção ocorreu nestes materiais. Porém, o processo inícial dos ensaios para ambos os adsorventes não aconteceu como o esperado, podendo ser constatado na Figura 5 a). Ocorreu uma adsorção gradativa ao longo do tempo, até os primeiros 45 min de ensaio, observando uma curva decrescente até atingir o máximo de adsorção, ou seja, o ponto de inflexão da curva. Após esse período a adsorção continuou por tempo médio de aproximadamente 25 min, obtendo, então, perfil característico de processos contínuos de adsorção, projetando a curva de efluência (Figura 5 b). Esse comportamento mostrou que a ativação (limpeza de sua superfície) do adsorvente com $\mathrm{N}_{2}$ a $80^{\circ} \mathrm{C}$ por $2 \mathrm{~h}$, não foi o suficiente para deixar todos os sítios de adsorção livres (superfície do adsorvente "limpa"). Segundo COLLINS et al. [49], o carvão ativado adsorve principalmente água e sua dessorção ocorre com aquecimento de $200{ }^{\circ} \mathrm{C}$ por $2 \mathrm{~h}$, provavelmente seja esse o fator do comportamento dos testes de adsorção dessa pesquisa não ter ocorrido como o esperado, não apresentando um perfil característico da curva de efluência de processos contínuos de adsorção.

A partir do ponto onde obteve-se o máximo de adsorção, ponto de inflexão, foi gerado o gráfico da Figura 5 b), que mostra a curva de ruptura ou de efluência. Na Tabela 4 são apresentados os dados da área acima da curva, que equivale a quantidade de gás adsorvida (em ppm) no leito da adsorção, até o tempo de saturação da coluna, quando chega em $\mathrm{C} / \mathrm{C}_{0}$ igual a 1 [29], sendo um valor fundamental para a comparação da eficiência dos adsorventes através de suas curvas de ruptura.

Os resultados mostraram que as adsorções totais, avaliadas desde o instante inicial do ensaio, ocorreram em 48 e 43 min para o CA e CA_5\% Nb, respectivamente, conforme pode ser observado na Figura 5a) e na Tabela 3 (ensaio total). As eficiências foram de 50 e 67\%, respectivamente para o CA e CA_5\% Nb. O máximo de adsorção (Figura 5 a) ocorreu com 242 ppm de CO para o CA e 337 ppm de CO para CA_5\%Nb. Após atingir o ponto de ruptura, a coluna saturou em 27 min para o adsorvente CA e 20 min para o adsorvente CA_5\% Nb, observando uma zona de transferência de massa até a saturação $\left(t_{s}\right)$ da coluna, para o carvão convencional e impregnado com nióbio, ou seja, com um tempo total de 75 min a coluna de carvão convencional deve ser regenerada e 63 min para o adsorvente impregnado, considerando as condições utilizadas neste trabalho.

Conforme apresentado na Tabela 3, o carvão impregnado com 5\% de nióbio apresentou melhor desempenho como adsorvente frente ao carvão convencional, com $18 \%$ a mais de gás adsorvido por grama de adsorvente. Foram adsorvidos um total de 10,5 L de gás CO no leito preenchido com o adsorvente impregnado, em comparação a 8,6 L de gás CO no leito de carvão convencional. Vale ressaltar que o carvão impregnado com nióbio adsorveu uma maior quantidade de $\mathrm{CO}$ em menor tempo, o que está provavelmente relacionado ao aumento no teor de oxigênio na superfície do material, favorecendo o processo de adsorção, como evidenciado na análise do EDS. Possivelmente o nióbio, em forma de óxido impregnado no carvão, faz interação de Van der Waals ou eletrostática com os pares de elétrons dos oxigênios do gás CO, sendo este um gás de molécula pequena (112,8 pm), polar e hidrofílica [32], facilitando a afinidade com adsorventes impregnados.

Além do aumento no teor de oxigênio na superfície do adsorvente, que favorece a adsorção do gás, a interação do orbital $d$ semipreenchido do elemento Nióbio pode favorecer a captura do CO no carvão ativado, dependendo da maneira que o metal impregnado no carvão ficou disposto na estrutura; o mesmo fenômeno que ocorre com o metal central do complexo de hemoglobina, onde o ferro reage com o grupo carbonil do monóxido de carbono, causando asfixia $[12,13,15]$. A Teoria do Orbital Molecular (TOML) e os Ligantes aceptores e doadores $\pi$ - TOML explica a interação deste fenômeno [34]. O CO é o ligante aceptor $\pi$ mais comum da química organometálica, estabiliza baixos estados de oxidação do metal e transfere a densidade eletrônica de orbitais $d$ para orbitais vazios do ligante, formando muitos compostos com o metal no estado de oxidação zero, como em $\mathrm{Ni}(\mathrm{CO})_{4}$ e $\mathrm{Fe}(\mathrm{CO})_{5}$; desta forma, é possível a formação do $\mathrm{Nb}(\mathrm{CO})_{6}$ no processo de adsorção. O trabalho de BARYBIN at. al. [50] mostra que análises mais apuradas, usando espectroscopias Raman e de Ressonância Magnética Nuclear de hidrogênio e carbono-13 - $\operatorname{RMN}\left\{{ }^{1} \mathrm{H}\right.$ e $\left.{ }^{13} \mathrm{C}\right\}$, devem ser realizadas para confirmação da TOML e para verificar a presença de niobatos de carbonil na estrutura do carvão ativado.

O gráfico apresentado na Figura 5 b), mostra os pontos das concentrações de $\mathrm{CO}$ em um instante $\mathrm{t}$ em relação a concentração inicial de $\mathrm{CO}\left(\mathrm{C} / \mathrm{C}_{0}\right)$, em função do tempo de adsorção do gás no adsorvente convencional e impregnado, em que os valores de $\mathrm{C} / \mathrm{C}_{0}$ variam de 0 a 1 com um gráfico em forma de $\mathrm{S}$, característico de modelos sigmoidais. Assim, foi proposto o modelo da distribuição não-linear sigmoidal de Boltzmann, apresentado na equação 5, para representar os dados experimentais de adsorção. A função sigmóide é uma 
função matemática de amplo uso em campos como a economia e na computação médica para descrever comportamentos mecânico de material biológico [51], frequência cardíaca [52], atividades metagenicas [53] e até adsorção em substratos [39]. Utilizou-se esta expressão matemática para descrever o comportamento dos dados experimentais. Os parâmetros foram expressos na Tabela 5.

As curvas de tendência obtidas a partir do modelo concordam com os dados experimentais, apresentando coeficientes de determinação $\left(\mathrm{R}^{2}\right)$ de 0,9980 e 0,9995 , para CA e CA_5\% $\mathrm{Nb}$, respectivamente, conforme apresentado na Tabela 5, o que indica que a equação sigmoidal de Boltzmann modelou de forma representativa os dados. Com esse método de distribuição é possível determinar o tempo de ruptura $\left(t_{r}\right)$, tempo ideal $\left(t_{i d}\right)$ e tempo de saturação $\left(t_{s}\right)$, a patir dos parâmetros obtidos da Tabela 5, em que $A_{1}$ e $A_{2}$ representam a fração molar do instante inicial $\left(\mathrm{C} / \mathrm{C}_{0(\mathrm{r})} ; t_{r}\right)$ e final $\left(\mathrm{C} / \mathrm{C}_{0(\mathrm{~s})} ; t_{s}\right)$ da curva de ruptura da Figura $\left.5 \mathrm{~b}\right)$; esses dados são apresentados na Tabela 6 . Também é interessante notar que o parâmetro $\mathrm{x}_{0}$ na Tabela 5 é o mesmo valor encontrado do tempo ideal $\left(t_{i d}\right)$ obtido pelo método do gráfico, ou seja, a curva de efluência obtida apenas com os dados experimentais (Tabela 6). O método gráfico possibilita conhecer os tempos a partir da interpolação do valor correspondido da relação $\mathrm{C} / \mathrm{C}_{0}$, em que $50 \%$ do menor valor de $C / C_{0}$ corresponte ao ponto ideal $\left(\mathrm{C} / \mathrm{C}_{0(\mathrm{id})} ; t_{i d}\right), 5 \%$ do valor mínimo é o ponto de ruptura $\left(\mathrm{C} / \mathrm{C}_{0(\mathrm{r})} ; t_{r}\right)$ e $95 \%$ é o ponto de saturação $\left(\mathrm{C} / \mathrm{C}_{0(\mathrm{~s})} ; t_{s}\right)$.

Comparando os dados obtidos pelo método experimental e pela modelagem matemática (Tabela 6), é possível notar uma pequena diferença entre os valores; isto se deve ao fato dos dados experimentais representarem os valores de porcentagem obtidos a partir do valor mínimo da relação $C / C_{O(\text { inicial })}$ encontrada no experimento; já os dados da modelagem pela equação sigmoidal de Bolztmann, determinam os valores exatos dos parâmetros: assíntota inferior, superior e ponto de inflexão, mostrando que quanto mais próximo do real o valor mínimo da relação $\mathrm{C} / \mathrm{C}_{0}$, mais concordantes os valores de tempo do ponto de ruptura encontrado por ambos os métodos. Essa afirmação pode ser constatada pelo valor mínimo registrado no ensaio com CA $\left(C / C_{0(\text { inicial })}=0,504\right)$, expresso na Tabela 4 , e a distribuição sigmoidal de Bolztamann encontrou para o parâmetro $A_{1}=0,507$ (Tabela 5), que representa a assíntota inferior $\left(C / C_{0(r)}\right)$, ou seja, o menor valor da fração molar antes de começar a crescer a curva ruptura. É possível observar na Tabela 6 que os valores do ponto de inflexão da curva sigmoidal do método gráfico e da distribuição de Bolztzmann são quase os mesmos, 17 e 16 min respectivamente. Também é possível notar na Tabela 5 que para o material CA, a distribuição sigmoidal de Bolztmann apresentou $\mathrm{A}_{2}=1,019 \cong 1,00$; visto que o valor máximo é 1 e na Tabela 6 o valor do ponto de saturação $\left(C / C_{0 s}=0,953\right)$ encontrado foi menor, pode-se concluir que a coluna com CA não atingiu $100 \%$ de saturação. A distribuição não-linear sigmoidal de Boltzmann pode ser usada como um modelo representativo dos dados de adsorção em leito fixo.

\section{CONCLUSÕES}

Os resultados das caracterizações dos materiais adsorventes mostraram que ocorreu com sucesso a impregnação de pentóxido de nióbio no carvão ativado, o que ficou evidenciado nas análises de MEV-EDS e FTIR. As análises de DRX não demonstraram mudanças estruturais na cristalinidade dos materiais. Pela análise de fisissorção de $\mathrm{N}_{2}$, foi possível constatar que houve diminuição na área superficial quando foi impregnando nióbio no carvão, porém houve uma conservação no diâmetro de poros do adsorvente, resultado este que não influenciou na performance do material impregnado, frente ao processo de adsorção.

Em relação aos ensaios de adsorção, o resultado de melhor eficiência ocorreu com o adsorvente carvão/5\% de nióbio, onde a presença de pentóxido de nióbio no material impregnado provocou o aumento de oxigênio superficial, evidenciado na análise de EDS, favorecendo o processo de adsorção.

A aplicação do modelo de distribuição não-linear sigmoidal de Boltzmann pode ser usado como um modelo representativo dos dados de adsorção em leito fixo destes materiais. Os resultados dos ensaios de adsorção de leito fixo de monóxido de carbono, utilizando carvão ativado convencional e carvão ativado com $5 \%$ de $\mathrm{Nb}$, mostraram que a adsorção ocorreu, demonstrando ser um processo promissor para minimizar as emissões desse gás e apresentando potencial para ser aplicado em processos industriais catalíticos onde o CO não é desejável e na redução das emissões veiculares, favorecendo assim o ambiente.

\section{AGRADECIMENTOS}

Ao CMCM (Centro Multiusuário de Caracterização de Materiais) pelas análises de MEV e DRX. Ao LAMAQ (Laboratório Multiusuários de Análises Químicas) pela análise de FTIR. Ao DEQ/UEM pelas análises texturais de adsorção/dessorção de $\mathrm{N}_{2}$. Ao instituto LACTEC por disponibilizar o módulo para os ensaios de adsorção. Ao Prof. Dr. Pedro da Costa Ramos Neto por ter disponibilizado o equipamento analisador de ga- 
ses. CNPq pelo apoio financeiro dado ao projeto ao qual este trabalho está vinculado. CNPq número do processo: 444137/2014-9.

\section{BIBLIOGRAFIA}

[1] BAIRD, C., CANN, M. Química Ambiental. 4a Edição, Porto Alegre: Bookman, 2011. 844p.

[2] ROCHA, J.C., ROSA, A.H., CARDOSO, A.C. Introdução a Química Ambiental, 2a Edição. Porto Alegre: Bookman, 2009.

[3] Revista Veja, https://veja.abril.com.br/saude/oms-classifica-poluicao-do-ar-como-fator-cancerigeno/

[4] GUARIEIRO, L.L.N., VASCONCELLOS, P.C., SOLCI, M.C. Poluentes Atmosféricos Provenientes da Queima de Combustíveis Fósseis e Biocombustíveis: Uma Breve Revisão. Revista Virtual Química, v. 3, p. 434-445, 2011.

[5] JORQUERA, H., MONTOYA, L.D., ROJAS, N.Y. Urban air pollution. Urban Climates in Latin America. Santiago, Chile. Springer, 2019.

[6] MARTONI, A.A. Air pollution and cancer. In: Clinical Handbook of Air Pollution-Related Diseases. Cham. Springer, p. 445-457, 2018.

[7] ARAUJO, D.M., et al. Estudos Comparativos entre Carvão Ativado e Resina de Troca Iônica para Adsorção de Ouro, Cobre e Ferro. http://dx.doi.org/10.1590/S0370-44672009000400008. ISSN 0370-4467. Rem: Rev. Esc. Minas [online]. 2009, v.62, .4, pp.463-468.

[8] SILVA, K.C.C., DAEMME, L.C., MACEDO, V., et al. AVALIAÇÃO DA TENDÊNCIA À FORMAÇÃO DE OZÔNIO DOS GASES DE ESCAPAMENTO DE UM VEÍCULO ABASTECIDO COM COMBUSTÍVEIS CONTENDO DIFERENTES TEORES DE ETANOL. v. 1, 2014.

[9] BARBOSA, S.M.M., et al. Air pollution and children's health: sickle cell disease. Cadernos de Saúde Pública, 2015.

[10] JIANRONG, M., ZHENYU, L., QINGYA L., et al. Fuel Processing Technology, v. 89, pp. 242-248, 2008.

[11] IBRAM- Instituto do meio ambiente e dos reursos hídricos do Distrito Federal. Principais Poluentes Atmosféricos. 2010.

[12] GODISH, T.. Air Quality. 4 ed. Boca Raton: Lewis Publishers, 2003.

[13] PROCKOP, L.D., CHICHKOVA, R.I. Carbon monoxide intoxication: An update review. Journal of Neurological Sciences, v. 262, p. 122- 130. 2007

[14] DAEMME, L.C., et al. Estudo preliminar sobre a influência do teor de enxofre do combustível na emissão de amônia em motociclos e veículos leves dos ciclos Otto e Diesel . v. 1, p. 1-20, 2014.

[15] SILVA, K.C,C., DAEMME, L.C., MACEDO, V., et al. AVALIAÇÃO DA TENDÊNCIA À FORMAÇÃO DE OZÔNIO DOS GASES DE ESCAPAMENTO DE UM VEÍCULO ABASTECIDO COM COMBUSTÍVEIS CONTENDO DIFERENTES TEORES DE ETANOL. v. 1, 2014.

[16] Ref: BRASIL. Ministério do Meio Ambiente, Conselho Nacional do Meio Ambiente, CONAMA. Resolução n 491, de 19 de novembro de 2018. Dispõe sobre os pa-drões de qualidade do ar. Diário Oficial da União, de 21 de novembro de 2018, seção 1, p. 155.

[17] Ref: BRASIL. Ministério do Meio Ambiente, Conselho Nacional do Meio Ambiente, CONAMA. Resolução $n^{\circ} 3$, de 28 de junho de 1990. Dispõe sobre os padrões de qualidade do ar, previstos no PRONAR. Diário Oficial da União, de 28 de agosto de 1990, p. 15937-15939.

[18] PARANÁ. Secretária do Estado do Meio Ambiente e Recursos Hídricos, SE-MA. Resolução n ${ }^{\circ}$, de 15 de abril de 2014. Define critérios para Controle da Qualidade do Ar como um dos instrumentos básicos da gestão ambiental para proteção da saúde e bem estar da população e melhoria da qualidade de vida, com o objetivo de permitir o desenvolvimento econômico e social do Estado do Paraná de forma ambientalmente segura. Diário Oficial, n. 9187, de 15 de abril de 2014.

[19] THOMMES, M., et al. Physisorption of gases, with special reference to the evaluation of surface area and pore size distribution (IUPAC Technical Report). Pure and Applied Chemistry, 2015.

[20] LIMA, A.D.J.B., et al. Emprego do carvão ativado para remoção de cobre em cachaça. Quimica Nova, v. 
29, n. 2, pp. 247-250, 2006.

[21] ARAUJO, D.M., et al. Estudos Comparativos entre Carvão Ativado e Resina de Troca Iônica para Adsorção de Ouro, Cobre e Ferro. ISSN 0370-4467. http://dx.doi.org/10.1590/S037044672009000400008. Rem: Rev. Esc. Minas [online]. 2009, v.62, n.4, pp.463-468.

[22] BRAGA, V.S., et al. Esterification of acetic acid with alcohols using supported niobium pentoxide on silica - alumina catalysts §. v. 135, pp. 106-112, 2008.

[23] CRUZ, M.H.C., et al. Liquid phase alkylation of anisole by benzyl alcohol catalyzed on aluminasupported niobia. "Catalysis Communications", v. 8, pp. 1650-1654, 2007.

[24] LUZ, A.B. Zeólitas: Propriedades e usos industriais. Série Tecnológica Federal CETEM. Rio de Janeiro, 1994.

[25] KAMINISHIKAWAHARA, K.K. PREPARAÇÃO DA ZEÓLITA SODALITA VIA TRATAMENTO TÉRMICO, SUA IMPREGNAÇÃO COM ÍONS Zn2+ E UMA AVALIAÇÃO PRELIMINAR DE SUA EFICIÊNCIA NA PRODUÇÃO DE BIODIESEL. Dissertação (Mestado em Bioenegia: Áea de concentação Biocombustíveis), Universidade Estadual de Ponta Grossa., v. 119, n. 3, 2015.

[26] BASTOS-NETO, M., MOELLERA, A., STAUDT, R., et al. Dynamic bed measurements of CO adsorption on microporous adsorbents at high pressures for hydrogen purification processes. Separation and Purification Technology. v. 77, p. 251-260, 2011.

[27] BANSAL, R.C., GOYAL, M.. Activated carbon adsorption, Book News, Inc., Portland, OR, 2005.

[28] MACHADO, N.R.C.F., RIZZO, R.C.P.; PEGUIN, R.P.S. Performance of catalysts with $\mathrm{Nb} 2 \mathrm{O} 5$ for hydrogen production from ethanol steam reforming. Acta Scientiarum Maringá, v. 24, n. 6, p. 1637-1642, 2002.

[29] NASCIMENTO, R.F., et al., Adsorção: aspectos teóricos e aplicações ambientais. Fortaleza: Universidade Federal do Ceará - UFC, 2014

[30] ZHAO, Y., et al. Nanostructured Nb2O 5 catalysts. "Nano Reviews", v. 3, n. 17631, p. 1-11, 2012.

[31] LESSA, M.O. Dissertação (Mestrado em Engenharia Química) - Universidade Federal do Rio Grande do Norte, .93f. 2012.

[32] DEAN, J. A. Lange's Handbook of Chemistry. 11 ed, ed. New York, USA.: New York, USA., 1973.

[33] IUPAC. Compendium of Chemical Terminology, 2nd ed. (the "Gold Book"). Compiled by A. D. McNaught and A. Wilkinson. Blackwell Scientific Publications, Oxford (1997). Online version (2019-) created by S. J. Chalk. ISBN 0-9678550-9-8. https://doi.org/10.1351/goldbook.

[34] SHRIVER, D.F., ATKINS, P.W., OVERTON, T.L., et al. Química Inorgânica. 4ª. Ed., Porto Alegre: Bookman, 2008.

[35] OLIVEIRA, M.W., et al. Estudo da adsorção de brometo de etídeo em resina XAD-7. Disponível em <http://www.scielo.br/scielo.php?script=sci_arttext\&pid=S0100-40422009000500010\&lng=pt\&nrm=iso>. acessos em 17 abr. 2020. https://doi.org/10.1590/S0100-40422009000500010. Quím. Nova, São Paulo, v. 32 , n. 5, p. 1134-1138, 2009.

[36] BOUCHELTA, C., MEDJRAM, M.S., BERTRAND, O., et al. Preparation and characterization of activated carbon from date stones by physical activation with steam. Journal of Analytical and Applied Pyrolysis: v. 82 , p. $70-77.2008$.

[37] HREŠČAK, J., et al. The influence of different niobium pentoxide precursors on the solid state synthesis of potassium sodium niobate. Journal of the European Ceramic Society. v. 33, p. 3065-3075. 2013.

[38] TREJDA. M., et al. New Nb and Ta-FAU zeolites-Direct synthesis, characterization and surface properties. Catalysis Today, v. 158, p. 170-177, 2010.

[39] LOPES, O.F., et al. Óxidos de nióbio: Uma visão sobre a síntese do Nb2O5e sua aplicação em fotocatálise heterogênea. Quimica Nova, v. 38, n. 1, p. 106-117, 2015.

[40] PAVIA, D.L., LAMPMAN, G.M., KRIZ, G.S. Introducão a Espectroscopia, São Paulo-SP. Cengage Learning, 2010.

[41] SIRCAR, S., GOLDEN, T.C., RAO, M.B. Activated carbon for gas separation and storage. Carbon, v. 34, n. 1, p. 1-12, 1996.

[42] PAULIS, M., et al. Preparation and characterization of niobium oxide for the catalytic aldol condensa- 
tion of acetone. Applied Catalysis A: General, v. 180, p. 411-420, 1999.

[43] GRAÇA, M.P.F., et al. $\mathrm{Nb}_{2} \mathrm{O}_{5}$ Nanosize powders prepared by sol-gel - structure, morphology and dielectric properties. Journal of alloys and compounds. v. 553, p. 177-182, 2013.

[44] JEHNG, J., WACHS, I. Structural Chemistry and Raman Spectra of Niobium Oxides. Chem. Mater., v. 3, p. 100-107, 1991.

[45] PRASETYOKO, D., et al. Preparation and characterization of bifunctional oxidative and acidic catalysts $\mathrm{Nb}_{2} \mathrm{O}_{5} / \mathrm{TS}-1$ for synthesis of diols. Materials Chemistry and Physics, v. 93, p. 443-449.

[46] SIRCAR, S., GOLDEN, T.C., RAO, M.B. Activated carbon for gas separation and storage. Carbon, v. 34, n. 1, p. 1-12, 1996.

[47] FERREIRA, R.C., LIMA, H.H.C., COUTO JUNIOR, O.M., et al. Utilização de carvão ativado de dendê in natura e funcionalizado em meio ácido na adsorção de paracetamol. Revista Matéria, v. 23, n. 1, 2018.

[48] SILVA, J.S., SANTOS, M.L., SILVA FILHO, E.C., et al. Subprodutos do babaçu (Orbignya sp) como novos materiais adsortivos: uma revisão. Revista Matéria, v. 24, n. 3, 2019.

[49] COLLINS, C.H., et al. Fundamentos de cromatografia. Campinas SP: Editora da Unicamp, 2006.

[50] BARYBIN, M.V., ELLIS, J.E., POMIJE, M.K., et al. Syntheses and Properties of Homoleptic Carbonyl and Trifluorophosphane Niobates: $[\mathrm{Nb}(\mathrm{CO}) 6]-, \quad\left[\mathrm{Nb}(\mathrm{PF} 3)_{6}\right)-$ and $[\mathrm{Nb}(\mathrm{CO}) 5] 3-$, https://doi.org/10.1021/ic980752i. Inorg. Chem., v. 37, n. 25, pp. 6518-6527. 1998

[51] BURIN, E., NIZ, M., SILVA, M. et al. Avaliação do modelo sigmoidal de Boltzmann na predição do comportamento mecânico de material biológico com propriedade viscoelástica não linear. VII Workshop de Informática Médica - WIM , Vila Velha, ES. (2007).

[52] LIMA, J.R.P. Frequiência cardíaca em cargas crescentes de trabalho: Ajuste sigmóide, ponto de inflexão e limiar de variabilidade da freqüência cardíaca. Tese de Doutorado, EEFE-USP, 1997.

[53] SILVEIRA, S.C., MUNIZ, J.A., SOUSA, F.A., et al. Modelos não lineares ajustados à produção acumulada de biogás provenientes de camas sobrepostas de suínos. DOI: http://dx.doi.org/10.18406/23161817v10n320181168. Revista Agrogeoambiental, Pouso Alegre, v. 10, n. 3, p. 91-103, jul./set.

\section{ORCID}

Elson Oliveira

Beatriz Bonk

Erika Pereira Felix

Roberta Caroline Pelissari Rizzo Domingues https://orcid.org/0000-0001-6546-4509

https://orcid.org/0000-0002-6312-097X

https://orcid.org/0000-0002-6951-7417

https://orcid.org/0000-0002-8775-4344 